\title{
Populações em situação de risco ambiental e vulnerabilidade do lugar em São Sebastião, Litoral de São Paulo
}

\section{Populations at Environmental Risk Situation and Vulnerability of Place in São Sebastião, Coast of São Paulo}

\author{
Francine Modesto dos SANTOS* \\ Eduardo José MARANDOLA JUNIOR**
}

\begin{abstract}
RESUMO
Riscos e vulnerabilidades são aspectos importantes do estudo da temática ambiental sob o ponto de vista demográfico, pois podem ser analisados a partir de populações e/ou lugares vulneráveis ou expostos a determinados riscos. O presente estudo analisa como as características sociodemográficas das populações em situação de risco tecnológico em São Sebastião, Litoral Norte de São Paulo, podem ajudar no enfrentamento dos perigos ligados ao maior terminal aquaviário da Petrobras (Tebar), localizado no centro do município. O estudo do Tebar analisa quais populações estão em situação de risco tecnológico. A partir da demografia de pequenas áreas (ou microdemografia), realizaram-se trabalhos de campo e entrevistas semiestruturadas com moradores em domicílios das áreas de risco no entorno do Tebar: os bairros Vila Amélia, Topolândia e Porto Grande, buscando compreender a percepção que as populações residentes nesses bairros têm dos riscos e quais estratégias podem mobilizar para enfrentar os perigos, elementos que permitem analisar a vulnerabilidade do lugar do ponto de vista demográfico.
\end{abstract}

Palavras-chave: percepção de risco; riscos tecnológicos; população e ambiente.

\begin{abstract}
Risks and vulnerabilities are important aspects of the studies about environmental issues under the demographic point of view. They can be analyzed from populations and/or places exposed to certain risks and vulnerabilities. The current study examines how the socio-demographic characteristics of the population at situation of technological hazards in São Sebastião, North Coast of São Paulo, can help us deal with hazards related to Petrobras' biggest waterway terminal (Tebar), located in the city's central area. It analyses which population is at risk of technological hazards. From micro-demography,
\end{abstract}

\footnotetext{
"Socióloga, Mestra em Demografia (UNICAMP) e doutoranda em Demografia pela Universidade Estadual de Campinas (UNICAMP). E-mail: fran_modesto@yahoo.com.br

** Doutor em Geografia (UNICAMP). Professor da Faculdade de Ciências Aplicadas da Universidade Estadual de Campinas (UNICAMP). E-mail: eduardo.marandola@fca.unicamp.br
} 
fieldwork and semi-structured interviews with dwellers at risk areas were carried out in the surroundings of Tebar (Vila Amélia, Topolândia and Porto Grande neighborhoods) with the intent to comprehend the risk perception they have and which are the mobilizations to face the hazards, elements that allow the analysis of the site vulnerability of place from the demographic point of view.

Keywords: risk perception; technological hazards; population and environment.

\section{Introdução}

Riscos tecnológicos e vulnerabilidade são aspectos importantes do processo de urbanização do município de São Sebastião localizado no litoral Norte de São Paulo. Este artigo analisa como a população exposta aos riscos tecnológicos do maior terminal aquaviário da Petrobras (Tebar), instalado na zona urbana do município, percebe esses riscos e concebe possíveis estratégias de enfrentamento.

O presente estudo examina como as características sociodemográficas das populações em situação de risco podem ajudar no enfrentamento dos perigos relacionados ao Tebar. A percepção do risco é considerada um fator fundamental na composição da vulnerabilidade, uma vez que as características sociodemográficas e culturais interferem na percepção e esses elementos afetam diretamente a capacidade de resposta aos perigos.

Utilizou-se para análise uma abordagem mixed-methods (métodos mistos), que inclui o uso de dados secundários (Censos Demográficos) e dados primários (trabalhos de campo e entrevistas). Foram realizadas entrevistas semiestruturadas com moradores em domicílios das áreas de risco no entorno do Tebar: os bairros Vila Amélia, Topolândia e Porto Grande, buscando compreender a percepção de risco das populações residentes nesses bairros e ampliar a capacidade analítica para compreensão das dinâmicas populacionais e ambientais, na microescala.

Os dados demonstram a heterogeneidade não apenas das áreas (bairros) impactados, mas também como os perfiis socioeconômico e demográfico de seus habitantes são aspectos que acarretam diferentes percepções do risco e condições de vulnerabilidade. Conclui-se que as estratégias de enfrentamento ao perigo, apesar de di- versificadas e operadas de formas distintas, possuem em comum a mobilização não apenas de ativos econômicos, como também de redes familiares e de relacionamento.

No primeiro item, faz-se uma descrição detalhada da implantação do Tebar em São Sebastião (SP) e os riscos a ela relacionados. No item dois, é definido o conceito de risco entendido por este trabalho, assim como se definem também os tipos de riscos relacionados às atividades do Tebar, que são os riscos tecnológicos. Este item mostra ainda o histórico de acidentes do terminal, as suas principais causas e como o Plano Apell (programa adotado pela Petrobras) auxilia no gerenciamento de riscos.

O item três mostra os dados demográficos da população em situação de risco no entorno do Tebar e, juntamente com as pesquisas de campo, revela como o município tem uma composição bastante heterogênea de suas três áreas de ponderação ${ }^{1}$ e as três áreas de estudo localizadas no centro do município também possuem características distintas entre si.

No quarto item, foram realizadas as análises das entrevistas qualitativas, buscando compreender e analisar as percepções de riscos das pessoas que vivem no entorno do Tebar, a forma pela qual se dá aceitabilidade ou não dos riscos e quais estratégias de enfrentamento os grupos poderiam ter para se defender em caso de acidentes. Para esta análise, foi fundamental conhecer a trajetória de vida, a composição familiar e a experiência do risco das pessoas entrevistadas, pois esses são elementos que compõem a percepção do risco e interferem na capacidade de resposta desses grupos, ou seja, na vulnerabilidade.

No último item, faz-se uma reflexão sobre novos riscos em função de novos empreendimentos que estão sendo instalados na região e estão diretamente relacionados ao Tebar e ao porto de São Sebastião; o que se

${ }^{1}$ Classificação da Fundação IBGE (2000 e 2010). 
pode apreender com a experiência do Tebar para esses novos projetos e os desafios de uma pesquisa multiescalar e de métodos mistos para os estudos de população e ambiente.

\section{Os riscos e o Tebar}

Até meados do século XX, o município de São Sebastião, no Litoral Norte de São Paulo, vivia em certo isolamento com relação à metrópole de São Paulo. Habitava nessa região a população caiçara, ${ }^{2}$ que se mantinha por meio da economia de subsistência baseada na agricultura (principalmente roças de milho, feijão, arroz, mandioca, banana e cana de açúcar) e da pesca (FRANÇA, 1954).

Com a inauguração do atual porto de cargas gerais, em meados dos anos 1950, a construção do Terminal Almirante Barroso (Tebar), da Petrobras, no início dos anos 1960 e o asfaltamento da rodovia Rio-Santos nos anos 1980, configurou-se um modelo desenvolvimentista na região que delineou as feições contemporâneas do município (CUNHA, 2003). A instalação do Tebar foi um marco na história de São Sebastião. O terminal representou na época oportunidades de empregos e hoje emprega cerca de 1.014 pessoas (CIA. DOCAS DE SÃO SEBASTIÃO, 2011 apud REIS, 2011).

A Petrobras se instalou em uma área onde estão localizados os bairros Vila Amélia (centro), Topolândia (centro-sul) e o bairro Porto Grande (centro-norte). Juntos, os três bairros correspondem a um espaço onde reside $19,45 \%$ da população no município, de acordo com o Censo Demográfico 2010, o equivalente a 14.374 pessoas (FUNDAÇÃO IBGE, 2010).

Instalado no sítio urbano de São Sebastião, o Tebar gerou, desde a sua implantação, uma série de impactos e riscos para a população residente e para o ambiente. A poluição ambiental causada pelo derramamento de petróleo dos navios pode ser considerada um aspecto negativo do advento do Tebar e até mesmo a localização dos tanques de armazenamento na área urbana, que representam perigo de incêndio, vazamentos, contami- nação do solo e da água, mau cheiro, são hoje os efeitos socioambientais resultantes do movimento dos grandes petroleiros na zona urbana deste município.

Diante deste contexto, indaga-se: quais são as populações expostas a estes riscos? Qual o seu grau de aceitação e de preparação para dar resposta a tais eventos?

Para responder tais perguntas, é necessário primeiramente caracterizar os riscos de natureza tecnológica associados às atividades do Tebar, conhecendo o histórico dos acidentes que já ocorreram desde a sua construção e os potenciais danos a que está exposta a população do entorno. Mas apenas entender a exposição aos riscos não é suficiente. É necessário entender a vulnerabilidade, ou seja, a capacidade de resposta e condições de enfrentamento de cada população e lugar aos perigos (MARANDOLA JR.; HOGAN, 2005; 2007).

Esta pode ser entendida como vulnerabilidade do lugar, compreendendo, ao mesmo tempo, as características dos meios natural e social, a partir de uma clara referência espacial (CUTTER, 1996; MARANDOLA JR.; HOGAN, 2009). O lugar dá unidade às dimensões demográfica, ambiental, social e cultural, servindo de base para a articulação entre as escalas de análise, incluindo a percepção de risco, que é ambiental e espacialmente mediada (PINHEIRO, 2006).

A percepção do risco é fator fundamental na resposta que as populações darão ao perigo. Considerando as escalas coletivas e individuais, de acordo com Burton, Kates e White (1978), a percepção individual e social dos riscos é fator determinante na aceitação ou não destes como reais, o que influenciará diretamente nas ações de enfrentamento e, se for o caso, mudança de comportamentos ou padrões de organização espacial. Por outro lado, ela é parte integrante da vulnerabilidade, já que características demográficas, espaciais e culturais interferem na percepção do risco, o que afeta diretamente a capacidade de dar resposta aos perigos (MARANDOLA JR., 2008).

Esta perspectiva faz parte da tradição de estudos dos perigos ambientais da geografia e da ecologia humana, entendendo a percepção como função cognitiva na relação homem-meio (SAARINEN, 1966; OLIVEIRA, 1977).

${ }^{2}$ Populações tradicionais da região litorânea. 
Com fundamentos psicossociais (SLOVIC, 2008), essa perspectiva mantém relação com as abordagens culturais do risco, conforme aponta Kates (1967), mas não dá a mesma ênfase à construção dos contextos socioculturais na formulação das representações dos riscos, conforme se tornará difundido a partir dos anos 1990, com mais ênfase (RENN, 2008).

A percepção envolve, portanto, tanto o contexto individual (história de vida, situação e posição, relações com o lugar, memórias) quanto os contextos de mediação sociais e culturais em que está inserida (família, grupo étnico, religião, situação econômica etc.). Para além de suas métricas, a percepção é entendida como fenômeno, expressando um ser-e-estar-no-mundo, como entende a fenomenologia (MERLEAU-PONTY, 1971).

Deste modo, adotaram-se métodos mistos (mixed-methods), que incluem a utilização de dados secundários (Censos Demográficos) e dados primários (entrevistas qualitativas baseadas em trabalhos de campo). As combinações de metodologias quantitativas e qualitativas e de múltiplas escalas vêm sendo defendidas por diversos pesquisadores (AXINN; PEARCE, 2007; MARANDOLA JR.; HOGAN, 2007) para ampliar a capacidade analítica e aprofundar a compreensão das dinâmicas populacionais e ambientais, além de permitir um olhar mais apurado, principalmente em microescalas.

Axinn e Pearce (2007, p. 2) argumentam que

[...] mixing multiple methods affords opportunities to use the strengths of some methods to counterbalance the weaknesses of other methods. Because all methods have strengths and weaknesses, combinations of multiple methods that achieve this counterbalancing aim are particularly valuable.

O uso das abordagens quanti-quali é um salto metodológico importante para que os estudos sobre riscos e vulnerabilidade possam avançar da constatação das áreas e pessoas vulneráveis, passando à discussão e à compreensão das alternativas que grupos demográficos, em cada lugar, têm para responder aos perigos (MARANDOLA JR.; HOGAN, 2007).

Ao lançar mão de dados do Censo Demográfico e de dados primários colhidos em entrevistas qualitativas, foi necessário também realizar a análise em diferentes níveis escalares, já que os fenômenos em tela têm escalas de produção e repercussão diferentes, afinal,

As relações de causalidade não se constroem em apenas uma escala, sendo fundamental que na investigação sobre População e Ambiente (P-A) haja a incorporação de escalas macro, médio e micro, para que possa haver a inter-relação entre os fatores causais e os termos de relacionamento entre a dinâmica populacional e o ambiente (MARANDOLA JR.; HOGAN, 2007, p. 209).

Para caracterizar a população, utilizaram-se dados demográficos do Censo 2000 e os disponíveis até o momento da publicação para o Censo 2010, utilizando para isso as duas agregações possíveis: os setores censitários e as áreas de ponderação. Procurou-se assim atribuir significado espacial aos recortes do Censo, concedendo aos recortes sentido ambiental e espacial.

Isso se fez necessário para poder se caracterizar a população de acordo com os níveis escalares distintos. Associaram-se aos recortes do Censo regiões do município (áreas de ponderação) e bairros (setores censitários) que possuem paisagem, história urbana, processos sociais, demográficos e econômicos semelhantes, dotando os recortes, originalmente compostos de forma operacional, de um significado espacial. Isso foi possível graças ao conhecimento do município e à avaliação de suas coincidências em relação aos recortes e à análise almejada.

Esta estratégia visa tanto refinar a análise em população e ambiente (estabelecendo uma correspondência direta entre os dados censitários e o lugar) quanto permitir uma análise em múltiplas escalas, possibilitando a apreensão de fenômenos de origens distintas que repercutem no lugar de estudo. De outro lado, se é necessário conhecer as especificidades da população e do lugar, é também fundamental ter os contextos maiores em que estes estão inseridos.

Espera-se, assim, contribuir para a construção metodológica de alternativas para estudos em população e ambiente que integrem dados de naturezas distintas e para as análises em várias escalas. Incorporar a análise em pequenas áreas é fundamental para investigar lugares específicos e as características demográficas daquela população que interferem na composição de sua vul- 
nerabilidade. A microescala, neste caso, é a escala da manifestação dos fenômenos e é por isso que todo o estudo está direcionado para sua investigação.

\section{Riscos ambientais e acidentes químicos ampliados em São Sebastião}

O risco é a tradução de uma ameaça, de um perigo para aquele que está sujeito a ele e o percebe como tal. Não há risco sem uma população ou indivíduo que o perceba e que poderia sofrer seus efeitos (VEYRET, 2007).

Para Renn (2008), o risco representa aquilo que as pessoas observam em sua realidade e aquilo que elas experimentam. Neste trabalho, adota-se uma abordagem integrada sobre o risco, entendendo-o como real e também como uma construção social, e a sua relação entre conceito e realidade se dá por meio da experiência de prejuízos reais que envolvem perdas de vidas humanas, impactos na saúde e no ambiente (DI GIULIO, 2010).

Deste modo, entende-se o conceito de risco como um fenômeno e, conforme aponta Marandola Jr. (2008), o risco como fenômeno existe tanto no plano perceptivo como no plano experiencial. Ele adquire uma dimensão sociocultural, que the atribui significado e valor ao mesmo tempo em que lhe dá existência.

Segundo Boholm (2003, apud DI GIULIO, 2010), o risco é extremamente contextual - o que é ou não considerado um risco depende de diversos fatores, como relações sociais, relações de poderes e hierarquia, crenças culturais, confiança nas instituições, conhecimento científico, experiências, discursos, práticas e memórias coletivas.

Autores como Veyret (2007) e Dagnino e Carpi Jr. (2007) classificam os riscos em: riscos naturais, riscos tecnológicos, riscos sociais e riscos ambientais (VEYRET, 2007; DAGNINO; CARPI JR., 2007). Esta pesquisa pretende aprofundar-se no estudo dos riscos ambientais e dos riscos tecnológicos a partir da análise dos riscos e perigos relacionados às atividades do Tebar e às populações que vivem no seu entorno, assim como características sociodemográficas dos grupos em situação de risco, a percepção que as populações têm desses riscos e a sua relação e experiência com o lugar.

Torres $(2000$, p. 53) discute teoricamente o conceito de risco ambiental, analisando que "a categoria risco ambiental tem sido frequentemente utilizada em disciplinas como, por exemplo, a geologia, ao classificar diferentes áreas urbanas e rurais sujeitas a fenômenos geológicos, tais como deslizamentos, afundamentos, inundações etc.”. O autor chama a atenção para inseri-la no debate das Ciências Sociais, de forma a discutir os aspectos técnicos relativos à operacionalização empírica dessa categoria e identificar as chamadas populações em situação de risco.

$\mathrm{O}$ argumento é que a categoria de risco ambiental pode ser particularmente importante para uma abordagem sociológica e demográfica da questão ambiental, uma vez que ela permite identificar e mensurar as diferentes características sociais e demográficas dos vários grupos populacionais expostos a diferentes tipos e graus de risco ambiental (TORRES, 2000, p. 54).

Nesse quadro conceitual, é difícil delimitar os grupos mais expostos a riscos ambientais ou então definir qual população (presente na área de risco) está sujeita a determinado perigo ambiental. Desta forma, há uma dificuldade em identificar as características que contribuem para a maior exposição de determinados grupos a riscos ambientais. Deste modo, Torres (2000) propõe cinco passos fundamentais da demografia de pequenas áreas que permitem a definição do que são populações sujeitas a riscos ambientais: (1) a identificação de uma fonte/fator potencialmente geradora de risco; (2) a construção de uma curva de riscos; (3) a definição de um parâmetro de aceitabilidade do risco; (4) a identificação da população sujeita a riscos; (5) a identificação de graus de vulnerabilidade dos grupos populacionais.

Ao seguir o método proposto por Torres (2000), outro aspecto importante para o entendimento dos riscos e de quais populações são residentes na área de risco diz respeito à espacialidade. $\mathrm{O}$ método proposto acima se aplica a estudos em escala micro, que buscam analisar as áreas de influência da fonte do risco. Este aspecto é fundamental para a análise do risco deste estudo, que investiga os riscos relacionados à implantação de um terminal marítimo de armazenamento e transporte de petróleo e derivados.

No campo da demografia, alguns trabalhos a respeito da temática de riscos relacionados a atividades industriais se destacam, como o trabalho pioneiro de Hogan (1993) sobre Cubatão (SP), o de Costa (1996) sobre 
o Vale do Aço (MG) e o de Druck e Franco (1997) sobre o Polo Petroquímico de Camaçari (BA). Eles apontam para o estudo em uma demografia de pequenas áreas, identificando relações entre a forma de organização da produção industrial, trabalho, meio ambiente e saúde, bem como as implicações que essas relações podem gerar em termos de riscos industriais, ambientais e de saúde das populações que vivem no entorno das indústrias altamente poluentes.

Assim como apontado por Torres (2000), Hogan (2000, p. 41) ressalta que uma abordagem promissora para captar as relações entre população-ambiente é o conceito de populações em situação de risco. O pesquisador aponta que a identificação e o estudo de ambientes em situação de risco são um caminho para analisar as consequências socioambientais de movimentos populacionais.

Esse estudo se concentra nos riscos tecnológicos associados diretamente ao Tebar, a partir de falhas internas (explosões, vazamentos, emissões e até mesmo contaminação das águas e solos) que podem afetar o entorno socioambiental. No entanto, a variedade de riscos vividos nestas áreas é muito maior, envolvendo também aqueles associados às chuvas, como o risco de deslizamentos dos morros (nos bairros Topolândia e Itatinga), inundações e transbordamento dos principais córregos da região central, o do Outeiro (centro) e o Mãe Izabel (Topolândia).

Inaugurado em 1969, o Tebar é um dos mais importantes terminais petrolíferos do país e o maior terminal aquaviário da Petrobras Transporte S.A. (Transpetro), subsidiária da Petrobras. O terminal dispõe de uma área operacional terrestre, onde estão instalados os tanques de armazenamento, sistemas de bombeamento, de combate a incêndio, oficinas de manutenção, área administrativa, uma agência marítima e a sede do Corpo de Bombeiros no município. Possui também uma área operacional marítima, constituída de píeres para rebocadores e dois píeres para atracação de navios (Píer Norte e Píer Sul), cada um deles com dois berços de atracação, podendo receber navios de até 300.000 toneladas de porte bruto e $23 \mathrm{~m}$ de calado (DEFESA CIVIL DE SÃO SEBASTIÃO, 2010).
Segundo informações do site da Transpetro, ${ }^{3} \mathrm{o}$ município de São Sebastião recebe petróleo nacional e importado por navios petroleiros e abastece por meio de oleodutos as quatro refinarias do Estado de São Paulo: a Refinaria do Planalto Paulista (Replan), em Paulínia, a Refinaria Henrique Lage (Revap), em São José dos Campos, a Refinaria de Capuava (Recap), em Mauá e a Refinaria Presidente Bernardes (RPBC), em Cubatão. O petróleo e derivados que entram e saem do terminal por navios têm como destino a exportação ou outros portos do território nacional.

O parque de tanques de armazenamento do terminal é constituído por 37 tanques, com capacidade total de $1.815 .310 \mathrm{~m}^{3}$, assim distribuída: 22 tanques de petróleo, 14 tanques de derivados de petróleo e um tanque de metanol. Está localizado na área urbana central do município, na planície litorânea entre o mar e a serra e foi nessa área que a Petrobras construiu seu pátio de tanques de armazenamento de petróleo a partir de 1961 (Figura 1).

Podem-se identificar pelo menos dois perigos potenciais relacionados ao Tebar. Os acidentes químicos ampliados e a poluição/contaminação do solo, águas marinhas e rios a partir da ocorrência de acidentes como vazamentos de óleo, incêndios e explosões.

Desta forma, a parte central do município - onde estão localizados o Tebar e seus bairros vizinhos (Vila Amélia, Topolândia e Porto Grande) - está sujeita à ocorrência de perigos provenientes da atividade petrolífera. Desde a instalação do terminal, há registros de diversos acidentes como derramamentos de óleo e incêndios em terra e na plataforma marítima.

Estes são acidentes químicos ampliados, ou seja, eventos agudos, tais como explosões, incêndios e emissões nas atividades de produção, isolados ou combinados, envolvendo uma ou mais substâncias perigosas com potencial para causar simultaneamente múltiplos danos, sociais, ambientais e à saúde física e mental dos seres humanos expostos (PORTO; FREITAS, 2000, p. 309).

Porto e Freitas (2000, p. 308) explicam que o acidente químico, dentro do risco químico e da indústria química, é importante pela sua especificidade. Uma de

${ }^{3}$ Disponível em: <www.transpetro.com.br>. Acesso em: 21 jul. 2010 


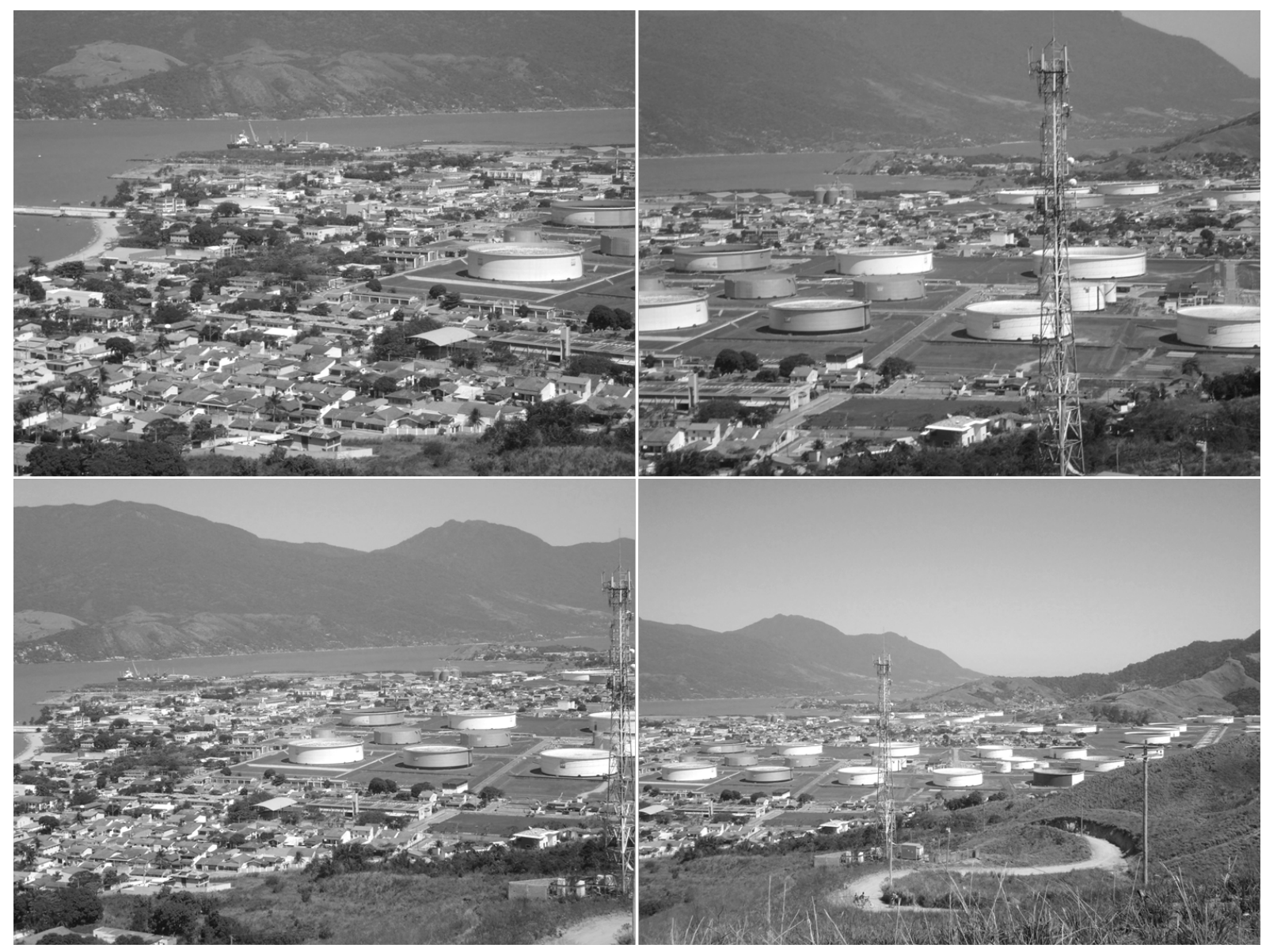

FIGURA 1 - Área urbana central de São Sebastião e tanques do Tebar, 2010.

Fotos: SANTOS (2011).

suas características é a relativa baixa probabilidade de ocorrência; porém, quando desencadeado, esse tipo de acidente pode provocar enormes tragédias humanas e ambientais, como as catástrofes ocorridas em Seveso/ Itália (1976), Vila Socó/Cubatão (SP), Cidade do México/México e Bhopal/Índia, as três em 1984.

Poffo (2000) baseia-se em registros de acidentes regulados pela Companhia Ambiental do Estado de São Paulo (CETESB) e pela Petrobras para analisar os vazamentos de óleo no mar que ocorreram desde 1974 até o ano de 1999. Neste período, há registro de 220 derramamentos de óleo no mar e foram movimentados 12.558 navios no Canal de São Sebastião. Segundo Poffo (2000), os modos de falhas mais frequentes que causaram vazamentos de óleo no canal de São Sebastião entre 1974 a 1999 foram: falha operacional durante o acompanhamento do enchimento de tanques e também falhas mecânicas em navios (Figura 2).

Um acidente marcante para a população de São Sebastião ocorreu em junho de 1984, depois que o vazamento de óleo de um dos tanques do Tebar atingiu um dos córregos mais importantes que cortam o centro do município, o córrego do Outeiro.

Este córrego, que tem sua nascente na Serra do Mar, teve seu curso natural "comprimido" ao longo dos anos entre os bairros e a instalação do Tebar. Hoje, o trecho urbano por onde ele passa tem limite entre a divisa com a área da Petrobras (atravessa um trecho 


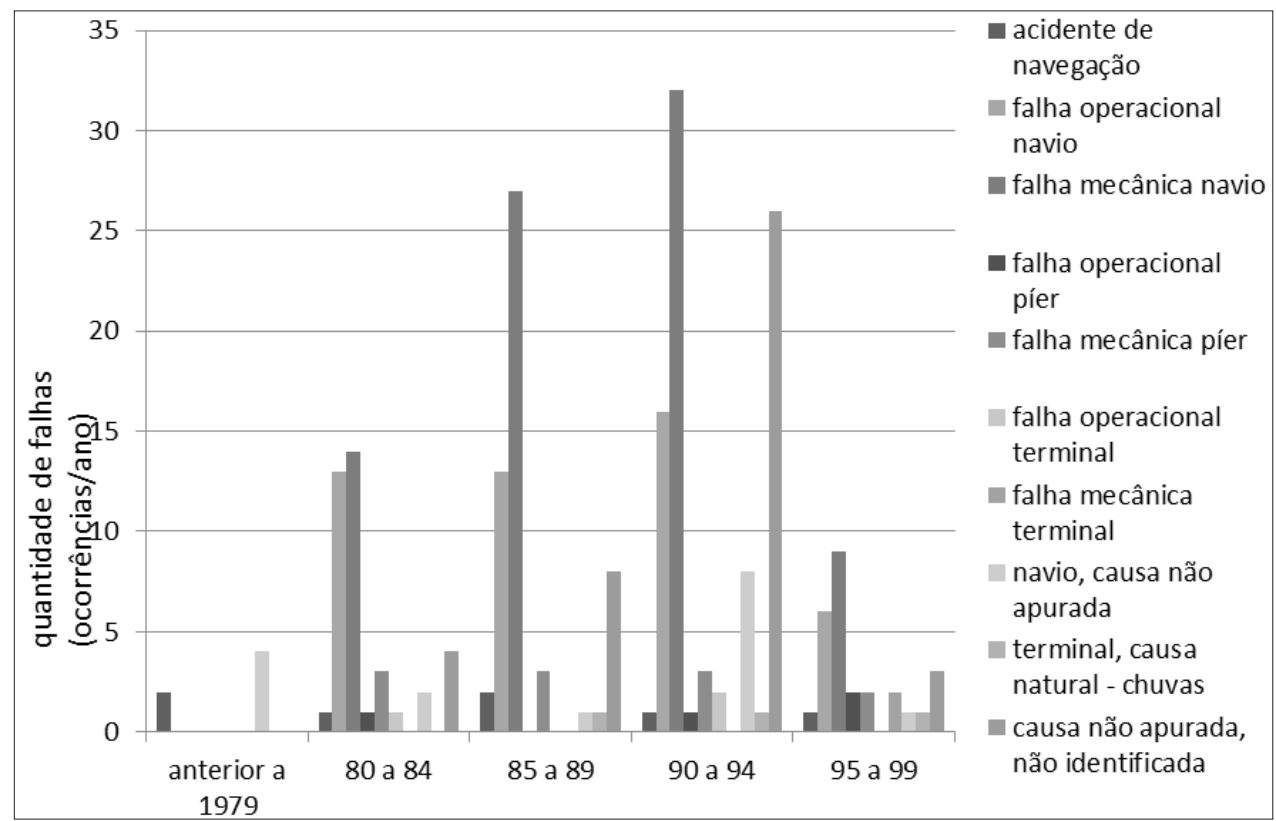

FIGURA 2 - Causas dos vazamentos de óleo no Canal de São Sebastião - quantidade de ocorrências registradas a cada cinco anos (1974-1999).

FONTE: Adaptado de Poffo (2000).

dos tanques ao fundo e o bairro Vila Amélia) e a área do aterro junto à orla da Rua da Praia, onde remanesce um trecho de mangue.

O óleo que vazou de um dos tanques do terminal atingiu o córrego do Outeiro e causou um imenso incêndio na área em que ele corta o bairro, atingindo algumas casas e o hospital da cidade. Segundo os jornais da época, o acontecimento causou pânico na população, que ainda se lembrava de eventos igualmente trágicos, ${ }^{4}$ bem como da explosão no mar em $1977 .{ }^{5}$

Após uma série de problemas e acidentes ambientais envolvendo substâncias químicas, ocorridos nas décadas de 1970 a 1980, órgãos governamentais se viram pressionados a promover diversos programas de gerenciamento de riscos impostos por atividades industriais.
A Petrobras adota como programa de gerenciamento de riscos o Programa Apell ${ }^{6}$ (Awareness and Preparedness for Emergencies at Local Level, em inglês), traduzido como Alerta e Preparação de Comunidades para Emergências Locais.

O Plano Apell é um programa de aplicação voluntária, elaborado em 1986 pelo Programa das Nações Unidas para o Meio Ambiente (Pnuma), que auxilia no gerenciamento de riscos e enfatiza a necessidade da participação conjunta da indústria, das autoridades locais (defesa civil, polícia, bombeiros, serviços médicos, órgãos ambientais etc.) e da comunidade em risco.

Com o Plano Apell em execução, a premissa é que, ciente de todas as informações sobre riscos que a indústria apresenta e os cuidados que ela mantém, além

\footnotetext{
${ }^{4}$ Episódio da Vila Socó, em 1984, bairro de Cubatão (SP), onde ocorreu um vazamento de óleo com posterior explosão e que teve cerca de 600 vítimas com morte. ${ }^{5} \mathrm{Na}$ madrugada de 21 de abril de 1977, os moradores foram acordados com um imenso clarão no mar durante o incêndio causado pelo choque do navio petroleiro Visconde de Cairu no píer do terminal; este foi um dos vazamentos que ocorreram no canal sem causa apurada e nem qual foi o volume de óleo derramado.

${ }^{6}$ Alerta e Preparação de Comunidades para Emergências Locais. Explicando o Programa Apell. Disponível em: <http://www.pnuma.org/industria_ing/documentos/ Explicando-Apell.pdf.
} 
das ações dos órgãos de governo, o cidadão estará mais seguro. A segurança vem da tranquilidade de poder decidir sobre sua vida e do conhecimento sobre como agir em caso de acidente (CUNHA, 2008, p. 3). Os objetivos do Plano Apell, segundo o manual elaborado pela Defesa Civil de São Sebastião, são:

1. Informar e conscientizar a comunidade interessada sobre os riscos decorrentes das atividades industriais vizinhas e sobre as medidas tomadas no sentido de se reduzir tais riscos, envolvendo-a no preparo para as possíveis situações de emergência;

2. Estabelecer e manter um plano global de emergência para acidentes tecnológicos, integrando, de forma cooperativa e organizada, os planos de emergência de empresas do município, notadamente o do Terminal da Petrobras, com os planos de ação dos órgãos oficiais, voltados para o atendimento a situações de emergência que possam afetar a comunidade local.

Faz parte do Plano Apell a demarcação das áreas de risco que são definidas como região da comunidade sujeita às prováveis consequências de um acidente tecnológico, delimitada para subsidiar a adoção de ações de alerta e remoção das pessoas presentes na mesma, com a finalidade de prevenir a ocorrência de vítimas (DEFESA CIVIL DE SÃO SEBASTIÃO, 2010). Segundo informações da Defesa Civil de São Sebastião, são realizados treinamentos/simulações de emergência anuais nas áreas de risco, nos quais as populações dos três bairros devem participar (não é obrigatório). Embora a população local tenha conhecimento sobre esses treinamentos da Apell, que ocorrem, sobretudo, com a participação das escolas, não sabe precisar de quanto em quanto tempo eles ocorrem.

Há pelo menos 12 atores institucionais envolvidos no processo Apell de São Sebastião: Prefeitura, Conselho Municipal de Defesa Civil (Consdec), Tebar, Cetesb, Polícia Militar do Estado de São Paulo, Corpo de Bombeiros $-11^{\circ}$ GI BB de São Sebastião, Hospital de Clínicas de São Sebastião, Desenvolvimento Rodoviários S.A. (Dersa), Empresa Bandeirante de Energia (EDP Bandeirante), Companhia de Saneamento Básico do Estado de São Paulo (Sabesp), Ecobus de São Sebastião e Telefonica S.A.
Isso mostra a amplitude do Plano, que tem por objetivo preparar as comunidades para situações de acidentes tecnológicos. Mas qual a efetividade do Plano em proteger a população do entorno? E qual seu papel na percepção dos riscos?

Mais importante do que isso, entretanto, é identificar as características da população exposta a tais riscos, que convive diariamente com o Tebar e que o tem como parte da paisagem local, ou seja, partícipe de uma relação sociocultural geograficamente centrada (BESSE, 2006). Identificar e caracterizar a população em situação de risco é fundamental para compreendermos suas percepções, estratégias e capacidade de enfrentamento de determinadas situações de perigo.

\section{Identificação das populações em situação de risco}

São Sebastião possui um território coberto pela Mata Atlântica (88,7\% do território do município), com uma extensão de cerca de $100 \mathrm{~km}$ de costa, composto por 33 praias ao longo de sua estreita faixa litorânea (SARACENI, 2010).

Em função das condições geográficas do município, caracterizado por um território extenso e montanhoso, com estreita faixa de terra, há trechos em que a Serra do Mar avança e não possibilita a ocupação humana, apenas a passagem da rodovia, que fica entre a serra e o mar. Além disso, devido a sua grande extensão e diferenciações geográficas, o município recebe três denominações que facilitam a compreensão em relação à localização dos bairros e auxiliam também a administração pública na gestão do município.

As denominações são Costa Norte, Centro e Costa Sul (Figura 3). A ocupação inicial ocorreu no Centro do município, que hoje corresponde aos bairros denominados Vila Amélia e Porto Grande (centro-norte), e posteriormente Topolândia (centro-sul).

As Costas Norte e Sul do município são bastante distintas e ao percorrer a rodovia Rio-Santos, que interliga São Sebastião a Bertioga (ao sul) e a Caraguatatuba (ao norte), nota-se as diferenças nas construções das casas e no comércio. Do Centro em direção à Costa Norte observa-se ocupações de médio e alto padrão, muitas 


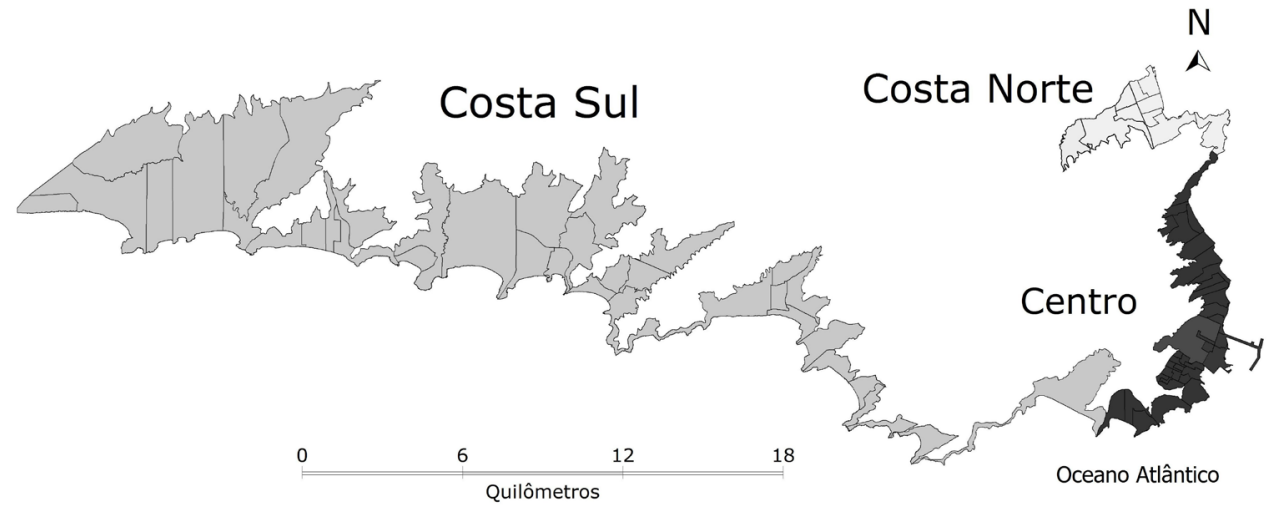

FIGURA 3 - Divisão Costa Norte, Costa Sul e Centro, São Sebastião, 2000.

FONTE: Fundação IBGE (2000b).

delas nas encostas da Serra, uma vez que a planície litorânea é bem estreita neste trecho do município. Em algumas praias, como a São Francisco, há a presença de barcos para a atividade pesqueira e uma urbanização menos densa em relação ao centro do município.

Em direção à Costa Sul, a partir da praia do Guaecá, onde em alguns trechos a planície litorânea é mais extensa, deparamos com casas mais próximas ao mar. Há diversos condomínios de casas de alto padrão construídos muito próximos à faixa marítima. Em Maresias, por exemplo, só é possível ter acesso à praia por meio de algumas passagens (como vielas) entre as casas e condomínios. O comércio da Costa Sul é bastante peculiar, acompanhando o padrão de vida das pessoas que a frequentam, como restaurantes mais caros, lojas de grife e estabelecimentos comerciais no padrão shopping center.

Os bairros e praias do Centro também têm suas peculiaridades, uma vez que esta área considerada central foi a primeira a ser povoada pelas populações caiçaras e onde ainda hoje se encontram muitas famílias tradicionais. Neste Centro também há bairros com casas de médio e alto padrão de construção, assim como nas Costas Norte e Sul e em alguns trechos há construções muito próximas à linha marítima, porém não de condomínios de alto padrão como na Costa Sul. Há exceções, como os bairros Topolândia, Itatinga e Olaria, que pertencem ao Centro, onde, porém, as casas têm um padrão de construção bem mais baixo em relação aos demais bairros do centro. O comércio em geral é mais movimentado entre os bairros Porto Grande e Vila Amélia e alguns dos atrativos turísticos do município, como a Igreja Matriz, o Museu e a Rua da Praia, também estão localizados nessa área central.

O estudo das áreas de ponderação (AP) do município de São Sebastião nos permite conhecer que há grandes discrepâncias em relação às três áreas definidas pelo Instituto Brasileiro de Geografia e Estatística (IBGE). De acordo com a instituição, o município de São Sebastião possui três áreas de ponderação, denominadas: Distrito São Francisco da Praia (norte), Distrito São Sebastião (centro) e Distrito Maresias (sul) (Figura 4). As porções norte, centro e sul do município têm características bastante distintas em relação a sua geografia, forma de ocupação, características populacionais e, inclusive, administrativas em relação à sede municipal.

Os dados do Censo Demográfico indicam que na área de ponderação São Sebastião, onde estão localizados o centro do município e o Tebar, localizava-se em 2000 grande parte dos domicílios e residia a maioria da população do município de São Sebastião $(37,4 \%)$ (Tabela 1). Embora o número de domicílios particulares permanentes tenha aumentado nas três áreas de ponderação em 2010, na área de ponderação São Sebastião o aumento foi menor, proporcionalmente ao total de domicílios e população residente neste Censo, passando de $37,4 \%$ em 2000 para $33,23 \%$ em 2010. 


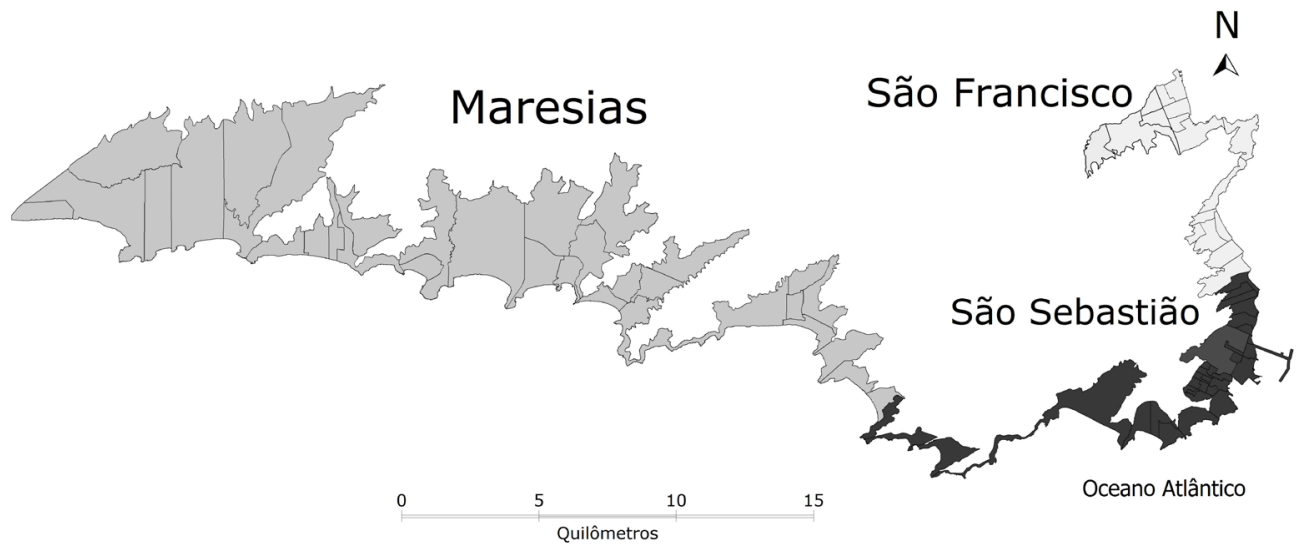

FIGURA 4 - Áreas de ponderação do município de São Sebastião, 2000.

FONTE: Fundação IBGE (2000b).

Ao contrário, na área de ponderação Maresias, ao sul do município, há um significativo aumento no número de domicílios e moradores de 2000 para 2010. As praias da Costa Sul, correspondentes a esta área de ponderação, concentram a maioria das atividades de veraneio, sendo que a população local está concentrada nos bairros Boiçucanga, Maresias e Juquey, enquanto que a Costa Norte abriga grande parte da população local (SARACENI, 2010). Esta região apresentou significativo crescimento de domicílios e população residente, muitos deles em áreas de risco, tornando-se em 2010 a área de ponderação mais populosa (42,13\%) (Tabela 1).

Os dados dos Censos 2000 e 2010 por espécie e situação dos domicílios nas três áreas de ponderação do município mostram que houve significativa alteração na distribuição da proporção de domicílios particulares permanentes. Se em 2000, na área de ponderação Maresias, havia maior porcentagem de domicílios particulares de uso ocasional, ${ }^{7} 56,6 \%$, esta porcentagem caiu para $32,9 \%$ em 2010. E enquanto $65,5 \%$ dos domicílios particulares

TABELA 1 - DOMICÍLIOS E POPULAÇÃO RESIDENTE NAS TRÊS ÁREAS DE PONDERAÇÃO, SÃO SEBASTIÃO, 2000 E 2010

\begin{tabular}{llcccc}
\hline & $\begin{array}{c}\text { Áreas de } \\
\text { Ponderação }\end{array}$ & $\begin{array}{c}\text { Total Domicílios } \\
\text { Particulares Permanentes }\end{array}$ & $\begin{array}{c}\text { \%opulação } \\
\text { Residente }\end{array}$ & $\mathbf{\%}$ \\
\hline Censo 2000 & São Sebastião & 6.093 & $\mathbf{3 7 , 4}$ & 21.717 & $\mathbf{3 7 , 4}$ \\
& Maresias & 6.095 & 37,5 & 21.518 & 37,1 \\
& São Francisco & 4.083 & 25,1 & 14.803 & 25,5 \\
& Total & 16.271 & 100 & 58.038 & 100 \\
\cline { 2 - 6 } Censo 2010 & São Sebastião & 7.844 & $\mathbf{3 3 , 2 3}$ & 24.080 & 32,68 \\
& Maresias & 9.891 & $\mathbf{4 1 , 9 1}$ & 31.051 & $\mathbf{4 2 , 1 3}$ \\
& São Francisco & 5.868 & 24,86 & 18.555 & 25,18 \\
& Total & 23.603 & 100 & 73.686 & 100 \\
\hline
\end{tabular}

FONTE: Fundação IBGE (2000a e 2010).

\footnotetext{
${ }^{7}$ Domicílio de uso ocasional é o domicílio particular permanente que na data de referência servia ocasionalmente de moradia. Ou seja, são aqueles usados para descanso de fins de semana, férias ou outro fim, mesmo que, na data de referência, seus ocupantes ocasionais estivessem presentes.
} 
SANTOS, F. M. dos; MARANDOLA JUNIOR, E. J. Populações em situação de risco ambiental e vulnerabilidade...

TABELA 2 - DOMICÍLIOS RECENSEADOS POR ESPÉCIE E SITUAÇÃO DO DOMICÍLIO (\%) NAS ÁREAS DE PONDERAÇÃO - SÃO SEBASTIÃO, 2000

\begin{tabular}{|c|c|c|c|c|c|c|c|}
\hline & $\begin{array}{l}\text { Áreas de Ponde- } \\
\text { ração }\end{array}$ & $\begin{array}{c}\text { Particular } \\
\text { ocupado }\end{array}$ & $\begin{array}{c}\text { Particular } \\
\text { não ocupado } \\
\text { - fechado }\end{array}$ & $\begin{array}{c}\text { Particular não } \\
\text { ocupado - uso } \\
\text { ocasional } \\
\end{array}$ & $\begin{array}{l}\text { Particular não } \\
\text { ocupado - vago }\end{array}$ & Coletivo & $\%$ \\
\hline \multirow[t]{3}{*}{ Censo 2000} & São Sebastião & 62,7 & 0,4 & 26,4 & 10,2 & 0,4 & 100 \\
\hline & Maresias & 35,7 & 0,1 & 56,6 & 6,2 & 1,3 & 100 \\
\hline & São Francisco & 65,1 & 0,5 & 23,9 & 10,4 & 0,1 & 100 \\
\hline \multirow[t]{3}{*}{ Censo 2010} & São Sebastião & 54,4 & 22,7 & 17,8 & 4,9 & 0,2 & 100 \\
\hline & Maresias & 26,2 & 36,6 & 32,9 & 3,8 & 0,5 & 100 \\
\hline & São Francisco & 55,9 & 22 & 15,8 & 6,3 & 0,1 & 100 \\
\hline
\end{tabular}

FONTE: Fundação IBGE (2000a e 2010).

ocupados em 2000 estavam na área de ponderação São Francisco, na Costa Norte, passaram a ser 55,9\% em 2010 (Tabela 2).

É interessante notar que a porcentagem de domicílios coletivos nas três áreas de ponderação é relativamente baixa em relação às demais situações apresentadas e, embora pudéssemos pensar que a maior parte dos domicílios coletivos estaria na área de ponderação São Sebastião, onde está localizado o terminal da Petrobras, eles estão concentrados na área de ponderação Maresias, na Costa Sul.

O tempo de residência também é um elemento muito importante, porque diz respeito tanto à experiência espacial que a pessoa tem da cidade - mais tempo, mais experiência -, que lhe permite conhecer tanto perigos quanto sistemas de proteção, quanto às experiências espaciais anteriores que a pessoa carrega e traz para o novo lugar, modificando-o também (MARANDOLA JR.; MODESTO, 2012) (Tabela 3).

Para conhecer as características sociodemográficas dos grupos sujeitos a riscos tecnológicos que residem nessa área central do município, recorremos à menor unidade de análise espacial do Censo Demográfico: o setor censitário. O setor censitário é a menor unidade territorial utilizada pelo Censo, ${ }^{8}$ com limites físicos identificáveis em campo e percorridos por um único entrevistador, respeitando os limites da divisão político-administrativa.

Em relação aos dados dos setores censitários, delimitamos a área de estudo a partir dos setores censitários do Censo 2000 que formam os bairros no entorno imediato do Tebar. São três: Vila Amélia/Centro, To-

TABELA 3 - TEMPO DE RESIDÊNCIA DA POPULAÇÃO EM SÃO SEBASTIÃO, 2000

\begin{tabular}{lcccccc}
\hline $\begin{array}{l}\text { Áreas de } \\
\text { Ponderação }\end{array}$ & $\mathbf{0 - 9}$ Anos & $\mathbf{\%}$ & $\mathbf{1 0 - 2 0}$ Anos & $\mathbf{\%}$ & $\begin{array}{c}\text { Mais de 20 } \\
\text { Anos }\end{array}$ & \% \\
\hline São Sebastião & 6.283 & $\mathbf{2 8 , 8 0}$ & 4.178 & $\mathbf{3 9 , 8 4}$ & 2.758 & $\mathbf{3 3 , 6 7}$ \\
Maresias & 10.626 & 48,71 & 3.493 & 33,30 & 666 & 8,13 \\
São Francisco & 4.904 & 22,48 & 2.817 & 26,86 & 4.768 & $\mathbf{5 8 , 2 0}$ \\
Total & 21.813 & 100,00 & 10.488 & 100,00 & 8.192 & 100,00 \\
\hline
\end{tabular}

FONTE: Fundação IBGE (Censo Demográfico 2000a).

\footnotetext{
${ }^{8}$ Os setores têm dimensão adequada à operação de pesquisas, em geral com base na quantidade de domicílios (cerca de 300 no urbano e 150 no rural, com variações aceitáveis de mais ou menos 50 e, seu conjunto esgota a totalidade do Território Nacional, o que permite assegurar a plena cobertura do País) (Fundação IBGE, 2000a, p.4-5).
} 
polândia e Porto Grande (Figura 5). Para o Censo 2010, o número de setores para estes três bairros foi mantido, com exceção do bairro Topolândia, que adquiriu mais quatro setores censitários.

Os dados do Censo 2000 mostram, na Tabela 4, que nos três bairros localizados no entorno do Tebar há pouco mais de 3.800 domicílios e uma população residente que chega a quase 14 mil pessoas, o que representa $23,56 \%$ do total de domicílios particulares permanentes do município e $23,43 \%$ da população residente contabilizados neste Censo.
Esses números apresentam modificações no Censo 2010: houve aumento no número de domicílios e população residente nesses três bairros do entorno do Tebar, que, juntos, somam mais de 14 mil moradores e pouco mais de 4.700 domicílios particulares permanentes, o que representa um aumento de $4,33 \%$ e $22,98 \%$, respectivamente.

Deste modo observa-se que, no último decênio, cada bairro, de maneira diferenciada, teve um aumento no número de pessoas em situação de risco. E esses números tendem a aumentar nos próximos anos, uma

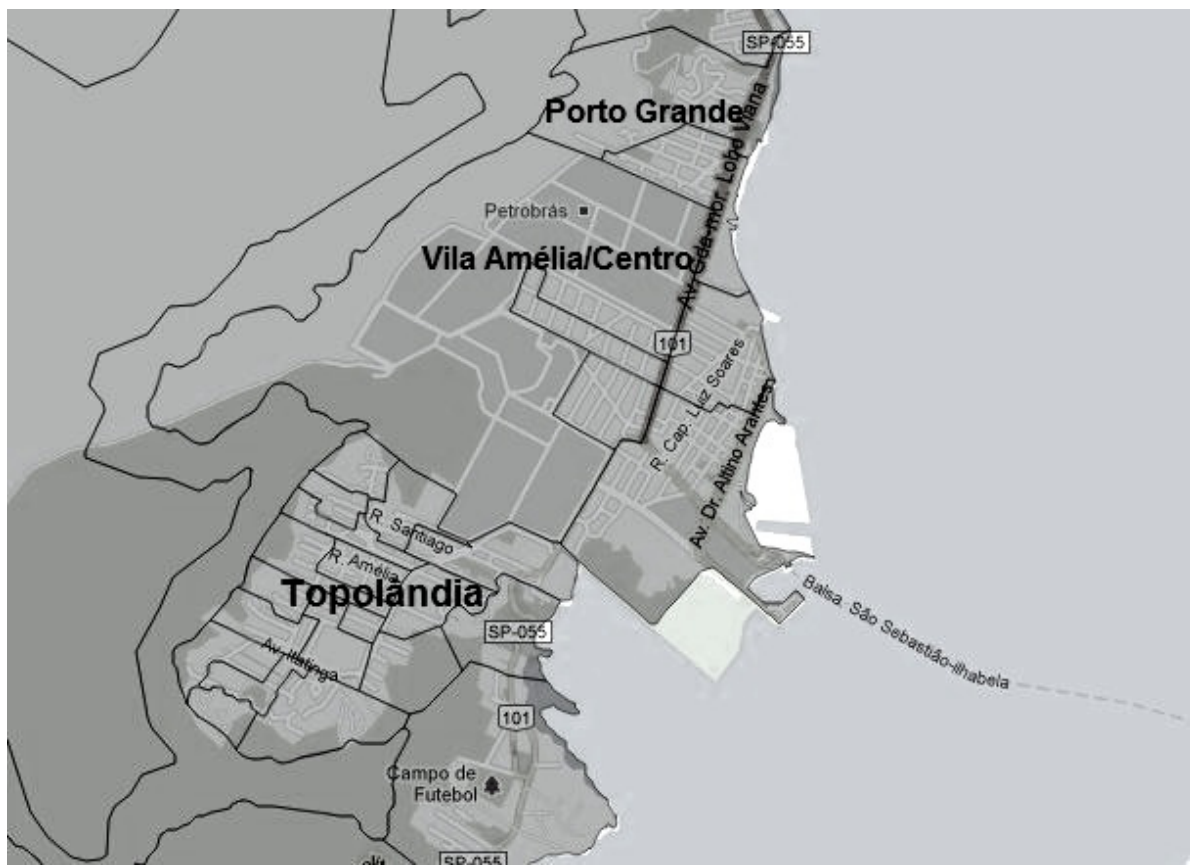

FIGURA 5 - Setores censitários no entorno do Tebar, São Sebastião, 2010. FONTE: Fundação IBGE (2010).

TABELA 4 - SETORES CENSITÁRIOS, $\mathrm{N}^{\circ}$ DE DOMICÍLIOS E POPULAÇÃO RESIDENTE NAS ÁREAS DE RISCO, SÃO SEBASTIÃO, 2000 E 2010

\begin{tabular}{lcccccc}
\hline & \multicolumn{3}{c}{ Censo 2000 } & \multicolumn{3}{c}{ Censo 2010 } \\
\hline \multicolumn{1}{c}{ Bairros } & Setores & Domicílios & Moradores & Setores & Domicílios & Moradores \\
\hline Vila Amélia/Centro & 05 & 1.101 & 3.687 & 05 & 1.193 & 3.293 \\
Topolândia & 10 & 2.347 & 8.844 & 14 & 3.028 & 9.767 \\
Porto Grande & 02 & 385 & 1.246 & 02 & 493 & 1.314 \\
Total & $\mathbf{1 7}$ & $\mathbf{3 . 8 3 3}$ & $\mathbf{1 3 . 7 7 7}$ & $\mathbf{2 1}$ & $\mathbf{4 . 7 1 4}$ & $\mathbf{1 4 . 3 7 4}$ \\
\hline
\end{tabular}

FONTE: Fundação IBGE (2000a e 2010). 
vez que novos empreendimentos estão sendo instalados na região, como a Unidade de Tratamento de Gás de Caraguatatuba (UTGCA), da Petrobras.

O Quadro 1 faz uma síntese das características gerais dos três bairros do entorno do Tebar, em termos de infraestrutura e características da população em situação de risco.

A análise dos setores censitários mostra que os três bairros do entorno do Tebar possuem características socioeconômicas completamente distintas. A partir da compreensão das condições sociodemográficas de cada bairro, pode-se conhecer qual população está em situação de risco e quais elementos poderiam ser favoráveis ao enfrentamento dos perigos.

No bairro Topolândia, os responsáveis por domicílios particulares permanentes dos setores censitários têm renda média mensal em torno de 600 reais e escolaridade baixa, em média cinco anos de estudo. Este bairro tem a maior densidade populacional dentre os três em estudo e a sua população é quase três vezes maior que a população do bairro Porto Grande.
No Porto Grande, os dois setores censitários que compõem o bairro têm a maior média de rendimento mensal do município e também a maior média de anos de estudo $(9,91)$. A infraestrutura do menor bairro entre os três estudados, tanto em número de setores como de domicílios e moradores, é considerada adequada para atender os moradores que, com melhores condições de vida, podem ter meios de transporte próprios e filhos que estudam em colégios particulares.

Na Vila Amélia, embora haja poucas residências de médio e alto padrão de construção, a renda média mensal dos responsáveis por domicílios permanentes está entre as mais altas do município ( $\mathrm{R} \$ 1.300,00)$. A população residente tem em média 8,2 anos de estudo, o que pode indicar melhores condições de vida de seus moradores, assim como no bairro Porto Grande.

A partir dos dados assinalados, mostra-se o pressuposto básico de que os perigos tecnológicos relacionados ao Tebar podem atingir os três bairros de modo heterogêneo. É possível pensar a partir das análises feitas acima que o bairro Topolândia possa ser o mais vulnerável entre os

QUADRO 1 - CARACTERÍSTICAS GERAIS DOS SETORES CENSITÁRIOS E POPULAÇÃO RESIDENTE NAS ÁREAS DE RISCO, SÃO SEBASTIÃO, 2000

\begin{tabular}{|c|c|c|c|}
\hline Setores censitários/bairros & Vila Amélia/Centro & Topolândia & Porto Grande \\
\hline Localização & Centro entre os tanques & Centro-sul & Centro-norte \\
\hline Características do bairro & $\begin{array}{l}\text { Ruas de lajotas de } \\
\text { concreto, poucas ruas } \\
\text { asfaltadas; casas de } \\
\text { médio e alto padrão de } \\
\text { construção; córregos a céu } \\
\text { aberto }\end{array}$ & $\begin{array}{l}\text { Ruas de lajotas de } \\
\text { concreto, poucas ruas } \\
\text { asfaltadas; casas de } \\
\text { médio e baixo padrão de } \\
\text { construção, muitas nas } \\
\text { encostas dos morros; } \\
\text { córregos a céu aberto }\end{array}$ & $\begin{array}{l}\text { Ruas de lajotas de concreto, } \\
\text { poucas ruas asfaltadas; casas de } \\
\text { médio e alto padrão de construção, } \\
\text { algumas nas encostas dos morros; } \\
\text { mais arborizado que os outros } \\
\text { dois; córrego estreito a céu aberto }\end{array}$ \\
\hline $\begin{array}{l}\text { Média do rendimento } \\
\text { nominal mensal dos } \\
\text { responsáveis por domicílio }\end{array}$ & $\mathrm{R} \$ 1.306,10$ & $\mathrm{R} \$ 640,64$ & $\mathrm{R} \$ 1.732,37$ \\
\hline $\begin{array}{l}\text { Média de anos de estudo dos } \\
\text { responsáveis por domicílio }\end{array}$ & 8,2 & 5,3 & 9,9 \\
\hline Meios de Transporte & $\begin{array}{c}\text { Principalmente carros; } \\
\text { ônibus não circulam dentro } \\
\text { do bairro }\end{array}$ & $\begin{array}{c}\text { Ônibus, carros e } \\
\text { principalmente bicicletas }\end{array}$ & $\begin{array}{l}\text { Principalmente carros; ônibus não } \\
\text { circulam no bairro }\end{array}$ \\
\hline
\end{tabular}

FONTE: Fundação IBGE (2000a) e pesquisa de campo 2010. 
três devido às suas características geográficas e ambientais que o expõem duplamente ao risco (riscos de deslizamentos e riscos tecnológicos) e ainda devido às características sociodemográficas e econômicas da sua população.

Contudo, a análise feita desta forma conduz a uma visão unidimensional da vulnerabilidade. Não há pessoas $100 \%$ vulneráveis, muito menos $100 \%$ invulneráveis (MARANDOLA JR.; HOGAN, 2009, p. 39). Embora os perigos do Tebar possam atingir as populações dos três bairros de maneiras diferentes, as pessoas podem ser vulneráveis a um determinado perigo e não vulneráveis a outro. Trata-se de um qualitativo intrínseco que permite responder aos perigos (MARANDOLA JR.; HOGAN, 2009, p. 39).

Deste modo, diversos elementos podem interferir na construção da vulnerabilidade. Já as estratégias que os grupos populacionais podem utilizar para o enfrentamento dos perigos podem ser independentes de quaisquer outros fatores.

A estrutura etária dos residentes nos três bairros também é bastante distinta. A Tabela 6 mostra que na Vila Amélia mais da metade da população residente $(52,6 \%)$ é de adultos e idosos (30-59 e 60 e mais anos de idade) em 2000 e que, em 2010, esse número chega a quase $60 \%$, enquanto no Topolândia a população está mais concentrada nos grupos etários de $\mathbf{1 5}$ a 29 e de $\mathbf{3 0}$ a 59 anos de idade, como mostram os dados dos dois Censos, embora este bairro apresente grande percentual de crianças (0-14 anos) - mais de 30\% em 2000 e 26\% em 2010. No Porto Grande, a proporção de pessoas entre
30 a 59 anos e 60 e mais anos de idade corresponde a mais de 50\% da população residente em 2000 (51,7\%) e aumenta para $62 \%$ em 2010.

Desta forma, entende-se que a composição etária dos três bairros pode influenciar na forma como as populações podem reagir diante dos perigos advindos das atividades do Tebar. Numa situação de risco, ter uma proporção de idosos como a dos bairros Vila Amélia e Porto Grande e uma proporção de crianças como a do Topolândia implica que se deve ter mais atenção para assistência nesses bairros, por serem grupos mais frágeis e que mais precisariam de ajuda e orientação em casos de perigos advindos dos riscos tecnológicos.

Sob esta ótica, de forma geral, os três bairros em estudo podem ser considerados os mais vulneráveis do ponto de vista da estrutura etária, pois somente eles representavam, em 2000, 30,1\% da população idosa do município e, em 2010, passaram a representar $41 \%$.

Porém, mais do que conseguir identificar a população em situação de risco nesses bairros do entorno, é necessário entender as heterogeneidades internas dos mesmos, das populações que neles habitam, vivenciam cotidianamente o risco e aceitam ou não os perigos relacionados ao Tebar. Assim, o conceito de vulnerabilidade do lugar nos permite incorporar esses elementos na microescala, de modo a poder conhecer as condições sociodemográficas que ajudam no enfrentamento dos riscos e perigos do lugar.

Esta abordagem procura circunscrever uma escala (uma região, uma cidade, um ecossistema, um bairro),

TABELA 5 - POPULAÇÃO RESIDENTE POR GRUPO ETÁRIO NOS TRÊS SETORES CENSITÁRIOS (\%), SÃO SEBASTIÃO, 2000 E 2010.

\begin{tabular}{lccc|cccr}
\hline \multicolumn{1}{c}{ Grupos } & \multicolumn{2}{c}{ Censo 2000 } & \multicolumn{3}{c}{ Censo 2010 } \\
\hline \multicolumn{1}{c}{ Etários } & Amélia & Topolândia & $\begin{array}{c}\text { Porto } \\
\text { Grande }\end{array}$ & $\begin{array}{r}\text { Grupos } \\
\text { Etários }\end{array}$ & $\begin{array}{c}\text { Vila } \\
\text { Amélia }\end{array}$ & Topolândia & $\begin{array}{c}\text { Porto } \\
\text { Grande }\end{array}$ \\
\hline $0-14$ & 19,88 & 30,83 & 19,82 & $0-14$ & 16,56 & 26,02 & 17,05 \\
$15-29$ & 27,45 & $\mathbf{3 1 , 8 0}$ & 28,41 & $15-29$ & 23,53 & $\mathbf{3 0 , 0 5}$ & 20,85 \\
$30-59$ & 39,27 & 32,17 & 41,73 & $30-59$ & 43,18 & 36,50 & 45,13 \\
60 e mais & $\mathbf{1 3 , 4 0}$ & 5,20 & 10,03 & 60 e mais & $\mathbf{1 6 , 7 4}$ & 7,43 & $\mathbf{1 6 , 9 7}$ \\
Total & 100,00 & 100,00 & 100,00 & Total & 100,00 & 100,00 & 100,00 \\
\hline
\end{tabular}

FONTE: Fundação IBGE (2000a e 2010). 
identificando nas interações sociedade-natureza os riscos e perigos que atingem o lugar, a partir das dinâmicas que configuram este tal espaço (MARANDOLA JR.; HOGAN, 2009, p. 7). Conforme argumentam Marandola Jr. e Hogan (2005, p. 18), "é justamente nessas abordagens (em microescala) que o olhar focado nas pessoas/famílias pode tornar-se mais útil e revelador, por permitir maior detalhamento e aprofundamento da realidade vivida por aqueles que habitam determinado lugar".

Cutter (1996) faz uma revisão do conceito de vulnerabilidade e identifica 18 definições diferentes. A definição de vulnerabilidade como perigo do lugar (hazard of place) será o conceito norteador desta análise, pois, segundo Cutter, este conceito resulta da interação entre vulnerabilidade biofísica e a vulnerabilidade social, em um domínio geográfico específico que resulta na vulnerabilidade do lugar. Nessa perspectiva:

[...] vulnerability is conceived as both a biophysical risk as well as a social response, but within a specific area or geographic domain. This can be geographic space, where vulnerable people and places are located, or social space, who in those places are most vulnerable (CUTTER, 1996, p. 533).

Marandola Jr. e Hogan (2009, p. 7) avaliam que olhar para os perigos e a vulnerabilidade do lugar é uma estratégia que permite, em microescala, apreender os elementos que interferem na produção, aceitação e mitigação dos perigos. Os autores sustentam a ideia de que:

A vulnerabilidade é, portanto, um qualitativo, ou seja, envolve as qualidades intrínsecas (do lugar, das pessoas, da comunidade, dos grupos demográficos) e os recursos disponíveis (na forma de ativos) que podem ser acionados nas situações de necessidade ou emergência (MARANDOLA JR.; HOGAN, 2009, p. 8).

Deste modo, a abordagem da "vulnerabilidade do lugar", como proposta por Cutter, permite encarar a percepção, a aceitação e o enfrentamento dos riscos e perigos do lugar como dimensões da vulnerabilidade, como aspectos que a revelam e permitem a discussão do ponto de vista da relação população-ambiente.

\section{Percepção dos riscos, confiança e estratégias familiares}

A análise circunscrita pela esfera do domicílio, das composições familiares, das trajetórias de vida e características sociodemográficas dos grupos populacionais em situação de risco no entorno do Tebar são elementoschave para pensar a vulnerabilidade do lugar. Essas esferas de estudo propostas são mediadoras da análise do lugar como estratégias demográficas que conduzem ao exame de como esses grupos que habitam a área de risco podem responder e superar situações de perigos.

Para compreensão da capacidade de resposta das populações em situação de risco no entorno do Tebar, primeiro deve-se conhecer qual é a população que pode ser atingida, suas peculiaridades e em que condições vivem. $\mathrm{O}$ estudo seguinte nos conduz a entender se os perigos poderiam atingi-la de modo homogêneo ou heterogêneo a partir de fatores demográficos que possam influenciar na capacidade de enfrentamento dos perigos.

Neste contexto, é de grande importância conhecer os arranjos familiares e a estrutura familiar das populações das áreas de estudo para entender um dos elementos-chave no estudo da vulnerabilidade, cujo componente importante envolve a capacidade de mobilizar ativos (neste caso as famílias) para o enfrentamento de determinados riscos e perigos, ou seja, a família como uma espécie de suporte.

Para tal, foram realizadas pesquisas qualitativas, a partir das quais foram analisadas as estratégias de enfrentamento dos perigos que podem ser mobilizadas pelas famílias entrevistadas, de acordo com a composição familiar e os recursos disponíveis, mediados por sua percepção e experiência dos riscos e perigos. Essas pesquisas possibilitaram compreender alguns elementos que permitem tangenciar a vulnerabilidade, como a percepção, a aceitação e o enfrentamento dos perigos. Esses elementos relacionados às características sociodemográficas das populações no entorno do Tebar também possibilitam conhecer aspectos que revelam a vulnerabilidade e permitem a sua discussão do ponto de vista demográfico (SANTOS, 2011).

A capacidade de responder ao perigo dependerá da quantidade e qualidade de recursos (ou ativos) sociais, 
ambientais, culturais e econômicos que cada lugar possui. A memória, a história e as experiências são instâncias fundamentais para coesão social do grupo e seu fortalecimento diante do perigo (DE PAULA; MARANDOLA JR., 2009, p. 2).

Para este trabalho, foram realizadas doze entrevistas semiestruturadas, quatro com moradores do bairro Vila Amélia, três do Topolândia, dois do Porto Grande e três com moradores de outros bairros próximos à área de risco, porém com envolvimento diário com a região central, fosse para estudo, trabalho ou ainda porque já residiram nesta área. A pesquisa não procurou ter representatividade estatística, portanto, é uma amostra não probabilística. Com as experiências sobre o risco obtidas nas entrevistas, teve-se o objetivo de analisar as variáveis demográficas estudadas em contextos concretos para então poder compreender a interação entre dados quantitativos e qualitativos, ou seja, a inter-relação entre eles.
Esta estratégia permite entender situações concretas da experiência do risco de forma compreensiva e, por isso, tem valor mesmo que com o uso de uma amostra muito pequena, porque é possível compreender os mecanismos de enfrentamento dos riscos a partir da relação que se tem com o lugar, bairro e cidade, ainda que a partir da pesquisa com um número pequeno de moradores.

O Quadro 2 apresenta uma visão geral dos entrevistados e elementos que revelam a sua percepção, entendimento ou não da Petrobras como um risco e as estratégias que utilizariam em caso de uma emergência como, por exemplo, um acidente de vazamento no terminal da Petrobras.

A coluna que mostra a composição familiar/ parentes próximos indica o arranjo familiar da pessoa entrevistada que, a partir das entrevistas, foi categorizado em: domicílio composto por pai, mãe e filho(s); domicílio de pessoa sozinha (domicílio unipessoal) ou domicílio com arranjo familiar monoparental (domicílio composto

\section{QUADRO 2 - SÍNTESE DAS ENTREVISTAS: PERCEPÇÃO DO RISCO E ESTRATÉGIAS DE ENFRENTAMENTO DOS PERIGOS}

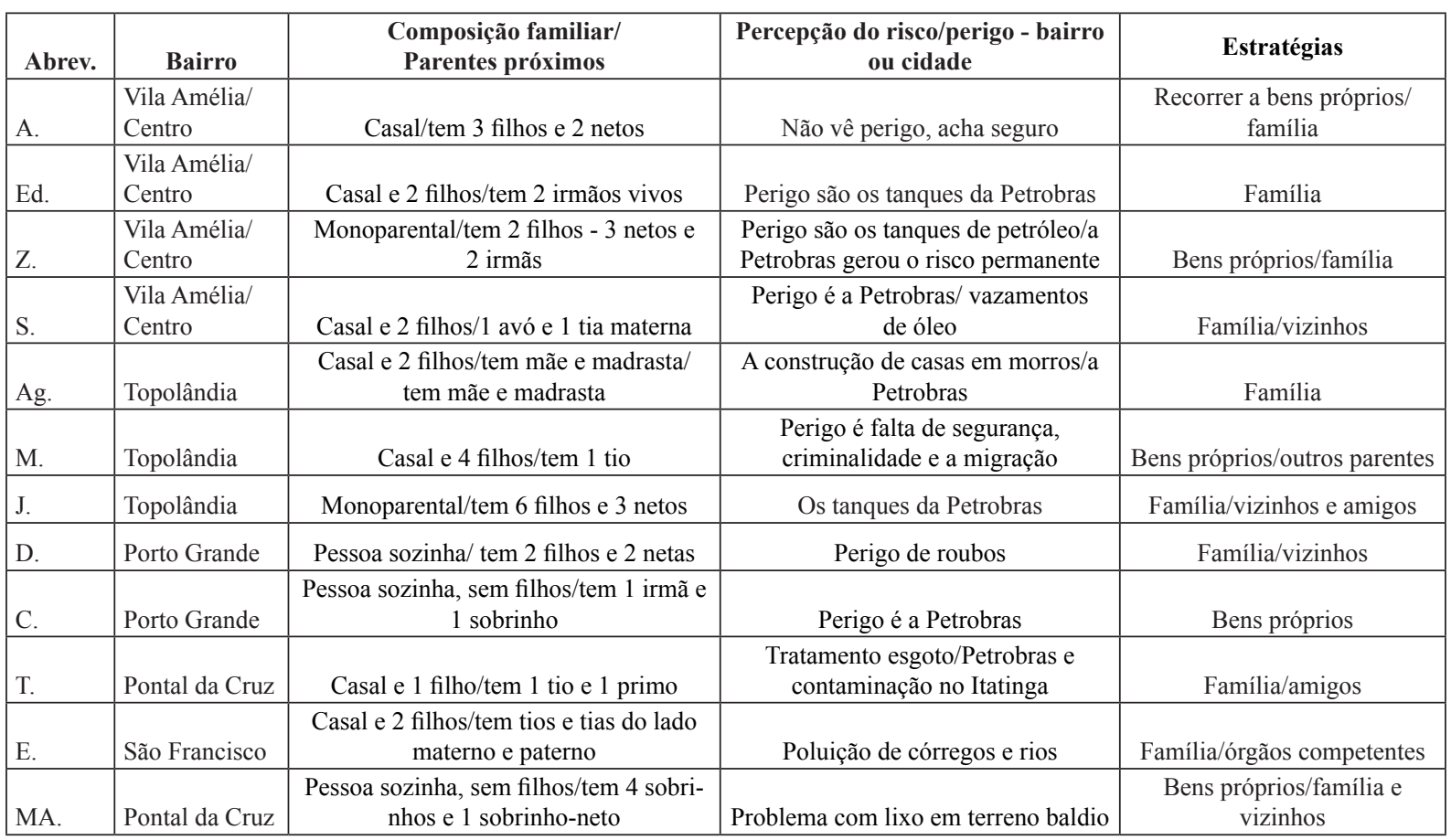

FONTE: Pesquisa de Campo (2010).

Por opção dos autores foi mantida a confidencialidade dos entrevistados e, por isso, seus nomes foram abreviados. 
unicamente pelo pai ou pela mãe mais filho(s)). Ressalta-se, neste item, a importância do suporte e apoio do grupo familiar, assim como vizinhos e rede de amigos. E na coluna estratégias vê-se que grande parte dos entrevistados recorreria à família quando perguntados sobre o que fariam em situações de perigo que atingissem a sua casa.

Na coluna sobre a percepção do risco/perigo no bairro ou na cidade, constam informações obtidas nas entrevistas a respeito dos perigos que os informantes percebem ao seu redor e no município como um todo. Muitos deles fizeram ligações diretas do perigo existente com os tanques do Tebar e suas consequências, como os vazamentos de óleo, tais como ocorreram em décadas anteriores e o caso recente de contaminação de óleo no bairro Itatinga, vizinho ao Topolândia.

Os entrevistados foram analisados de acordo com sua idade, trajetória de vida, composição familiar, experiência do risco/perigo, percepção dos riscos e perigos da cidade e do bairro, medo ou não de morar na área de risco e estratégias de enfrentamento dos perigos/recursos disponíveis.

Das doze pessoas entrevistadas, seis reconhecem diretamente os tanques de petróleo do terminal da Petrobras como um perigo do bairro ou cidade, mas consideram que é seguro viver em volta dos tanques por pelo menos dois motivos:

- Confiam no sistema de segurança da empresa. Neste caso o grau de aceitação do risco se dá em função do seu conhecimento e da preparação para crise (treinamentos - Apell); ou

- Sua experiência do risco/perigo mostra que os eventos que já ocorreram em décadas passadas não causaram danos marcantes para a população e ainda porque nunca mais esses eventos ocorreram.

Esses resultados demonstram que as percepções de risco se constroem em função do grau de confiança que o público tem nas instituições responsáveis pela administração e gestão do risco.

A comunicação do risco e a preparação das comunidades do entorno do Tebar executadas pelo Plano Apell auxiliam na legitimação do sistema de segurança da empresa. De acordo com Cunha, R. (2008, p. 39), “a aceitação, por parte da comunidade, de viver com o risco decorrente de uma instalação perigosa, se torna possível por meio do acesso à informação e da participação nos planos de emergência". A comunicação do risco agiria no sentido de amenizar a desconfiança.

Silva, G. (1999, p. 17) menciona a contribuição de Giddens, ao colocar que as pessoas têm "confiança nos sistemas peritos" como um estratagema moderno para lidar com os riscos. Giddens (1991, p. 122) aponta que, com o desenvolvimento dos sistemas abstratos (sistemas peritos) criados pela sociedade industrial, criou-se uma confiança impessoalizada, que se torna indispensável à existência social; há uma forte necessidade psicológica de achar outros em quem confiar.

No caso da área de estudo, o Plano Apell se mostra eficaz no sentido de conseguir tranquilizar a população sobre os riscos que a atividade do terminal pode gerar. Por meio do conhecimento e percepção do risco, o seu grau de aceitação e confiança nos sistemas peritos se torna maior, conjuntamente com o preparo da população para que saiba agir em momentos de acidentes.

Em sua maioria, os entrevistados mostram que a confiança que têm na segurança do Tebar é fundamentada na tecnologia atestada pela empresa e na experiência que eles têm do risco, pois não ocorreram mais acidentes nos últimos anos: "Eu não tenho medo de morar aqui próximo aos tanques, porque eu acho que hoje com a evolução da tecnologia não tem por que ter medo e eles fazem treinamentos também. Minha mãe conta que antes tinham muitos acidentes, mas hoje não acontecem mais" (S., 21, moradora da Vila Amélia).

A construção social do risco também é um elemento que interfere na sua percepção e aceitação. Apesar de o risco do Tebar estar impresso na paisagem do centro do município, não se manifesta cotidianamente como estando associado a grandes desastres.

A abordagem cultural do risco proposta por Douglas e Wildavsky (1982) entende que o risco é construído socialmente e só desta forma pode ser entendido. Segundo esta dimensão, a aceitabilidade dos riscos é mediada pela cultura e pelo processo social. Os autores analisam ainda que os estudos sobre a aceitabilidade do risco feitos por Baruch Fischhoff, Sarah Lichtenstein e Paul Slovic concluem que o risco aceitável é sempre uma questão política. "Values, beliefs, uncertainties are an integral part of every acceptable-risk problem. As a result, there are no value-free processes for choosing between risky alternatives" (DOUGLAS; WILDAVSKY, 1982, p. 4). 
De acordo com Di Giulio (2010), os estudos conduzidos por Brian Wynne nas décadas de 1980 e 1990 mostraram que o público leigo não age de modo irracional, mas segue outra racionalidade social e/ou subjetiva que inclui suas próprias experiências e falhas dos peritos.

Esses estudos evidenciaram que a confiança é uma questão fundamental para a compreensão das controvérsias entre o público leigo e os sistemas peritos e que as percepções de risco se constroem em função do grau de confiança que o público tem nas instituições responsáveis pela administração e gestão do risco. As respostas leigas aos riscos e às informações sobre os riscos são apoiadas numa racionalidade que emerge de suas experiências e julgamentos de credibilidade e confiança em relação às instituições que assumem o seu controle, envolvendo questões como o desempenho, as atitudes, a abertura ou transparência das indústrias e das agências reguladoras (DI GIULIO, 2010, p. 26).

Há ainda outro aspecto importante da aceitabilidade do risco relacionado ao que o Tebar representou e ainda representa para o município em termos de desenvolvimento. A aceitabilidade do risco, a princípio, esteve muito relacionada à ideia de que $\mathrm{a}$ instalação do terminal traria desenvolvimento para o município, como de fato ocorreu, pois diversas melhorias para a vida dos povos caiçaras aconteceram na fase inicial do empreendimento e, entre elas, a principal foi a oferta de empregos.

Porém, nos dias atuais, 41 anos após a instalação do Tebar em São Sebastião, é possível examinar com outro olhar como a população do entorno avalia os prós e contras da presença do terminal no centro do município. Embora a vinda da empresa para São Sebastião tenha representado uma perspectiva de progresso para o município e seus moradores e, por isso, houve um grande entusiasmo da população em receber a construção do Tebar na cidade, isso só ocorreu de fato nos primeiros anos de construção e instalação do terminal. Hoje, devido às diversas mudanças nas estruturas de gestão da empresa e à própria modernização tecnológica, não há mais oferta de empregos como antes e isto fica claro nas falas dos moradores, que sentem um afastamento da empresa que os ajudou no começo e agora segue seu rumo sem compartilhar benefícios com a população que a acolheu.
Com relação ao aspecto da composição familiar, este é um importante recurso para as populações que residem no entorno do Tebar. Grande parte dos entrevistados tem como primeira opção recorrer a parentes próximos, familiares que moram no mesmo bairro ou proximidades. Porém, moradores com outra condição material, com idade avançada e também com família pequena ou pessoa sozinha, se preocupam em não incomodar parentes próximos em primeira instância, mas sim recorrer a bens próprios acumulados durante a vida e sistemas privados de proteção em situações de perigo.

Um exemplo é A., que viveu durante toda sua vida (78 anos) no bairro Vila Amélia e, portanto, presenciou os acidentes anteriores relacionados ao Tebar, mas hoje acredita que já não há mais problemas em viver próximo ao terminal, portanto, sua percepção é de que é seguro viver no entorno. A. revelou que em uma situação de perigo, em que tivesse que deixar sua residência, recorreria a seus próprios bens, se fosse o caso se hospedaria em algum hotel e, em último caso, recorreria a sua filha que mora no bairro Porto Grande.

Esta estratégia diante do perigo foi comentada por mais quatro entrevistados, três deles com mais de 60 anos de residência na região central do município e com estrutura familiar do tipo unipessoal (pessoa sozinha) ou monoparental (pai ou mãe com filho(s)) que confiam no sistema de segurança da empresa e não consideram que os tanques sejam um perigo que ameace suas vidas, mas de qualquer forma têm como se proteger em primeira instância com seus próprios bens acumulados durante a vida. No geral, pessoas com menor tempo de residência nos bairros do entorno do Tebar (ou por ser migrante ou pessoa mais jovem), com exceção de Ed., J. e D., que vivem em São Sebastião há 60, 44 e 69 anos, respectivamente, e que vivem em famílias compostas por casais e filhos, que disseram recorrer a parentes próximos em caso de emergência.

Desta forma, nota-se que famílias mais numerosas ou com parentes mais próximos pensam no recurso familiar ou amigos e vizinhos em primeiro plano, enquanto que famílias menores ou pessoas sozinhas com parentes mais distantes decidem por recorrer ao suporte familiar em segundo plano.

Assim, a partir da observação de algumas estratégias escolhidas pelas famílias que vivem em situação 
de risco ambiental, verificam-se aspectos importantes da vulnerabilidade: os ativos econômicos e sociais que podem ser mobilizados pelas famílias para o enfretamento de situações de perigo.

Segundo Kaztman e Filgueira (2006, p. 71), para explicar os diferenciais de vulnerabilidade em domicílios urbanos, há uma perspectiva que usa como fator explicativo o grau de ajuste entre os ativos que os domicílios podem mobilizar e, ainda, os requisitos de acesso às fontes de renovação e acumulação dos ativos necessários. A esses ativos este autor denomina estrutura de oportunidades.

Desta forma, observa-se que a capacidade de resposta aos perigos do Tebar está muito relacionada às estruturas de oportunidades existentes, constituídas pelas famílias e bens próprios acumulados durante a vida. Embora a dimensão da renda seja um aspecto importante, o conjunto de necessidades básicas atendidas com a ajuda de familiares é a garantia de que é possível mobilizar este ativo social não vinculado diretamente à situação socioeconômica em momentos de adversidades.

Há outro elemento que pode interferir na capacidade de resposta aos perigos: o tempo de residência no município. O tempo de moradia é importante, pois além de o morador ter mais tempo de experiência do risco do lugar, favorece o estabelecimento de relações de vizinhança que podem ser importantes ativos a serem mobilizados. Isso fica evidente nas estratégias diferenciadas entre os mais antigos e os migrantes mais recentes, acionando redes de parentes ou recorrendo a sistemas estatais e privados de proteção.

\section{Mudanças ambientais e os desafios escalares $e$ de informação}

São Sebastião e o litoral de São Paulo, como um todo, estão vivendo um dos períodos de maior transformação dos últimos 50 anos. A exploração das recém-descobertas reservas de petróleo e gás na costa brasileira, empreendimentos industriais e as consequentes expansões na infraestrutura viária e portuária prometem trazer desenvolvimento, emprego e, por esta via, qualidade de vida à população. Um discurso que se repete há mais de 100 anos durante a era do industria- lismo em todo o mundo. Mas o seu reverso são os riscos tecnológicos (como os gerados pelo Tebar) e a produção de desigualdades, efeito colateral incontornável do atual modelo de desenvolvimento.

As mudanças ambientais locais e regionais são intensas e significativas, especialmente considerando-se a condição frágil do ecossistema costeiro e sua pouca resiliência. A expansão da urbanização e a atratividade que o desenvolvimento econômico está produzindo têm seu reverso na ocupação de áreas de risco e no comprometimento de áreas de amortecimento, o que torna mais crítica a gestão das áreas de risco e a própria implementação de planos de gestão e rotas de fuga, no caso de acidentes. O Tebar, incrustado no meio da cidade, entre o centro histórico e a serra, se torna agora apenas um dos exemplos de um modelo de ocupação baseado na combinação de adensamento da ocupação, ambiente frágil e grandes plantas industriais potencialmente poluidoras.

Como se pode apreender da experiência do Tebar, informar a população sobre os riscos decorrentes da atividade industrial e quais as formas de se proteger em casos de emergência não bastam para promover uma boa condição de proteção. Na verdade, tais ações se revelam como estratégias que, de certa forma, permitem a aceitação do risco por parte das populações do entorno, ou seja, há uma legitimação do risco ambiental pela população impactada. Mas a população, neste sentido, continua afastada da tomada de decisão e sofrendo impactos de um determinado modelo de desenvolvimento.

O pouco conhecimento que se tem sobre a efetividade do Plano Apell, no caso do Tebar, nos leva a pensar se de fato tal estratégia está cumprindo seus objetivos. Se há algum tipo de inoperância do Plano, pode ser algo muito pior do que não tê-lo e, nesse sentido, não há indícios convincentes de que a população esteja familiarizada com o processo Apell e que em um caso de emergência ela saiba efetivamente como agir.

Entende-se que o Plano Apell de certa forma interfere na forma como as populações do entorno percebem os riscos, uma vez que as ações do Plano contribuem para amenizar a sensação de insegurança diante dos perigos. Desta forma, deve ser feita uma discussão mais ampla e uma avaliação do Plano Apell no município de São Sebastião a partir do plano de gestão dos riscos e perigos propostos pelas autoridades responsáveis. 
Vainer (1990) aponta a necessidade de considerar critérios qualitativos para as metodologias de avaliação dos impactos de grandes projetos de investimento, visando ao planejamento regional e a um novo campo de discussão frente à instauração de projetos de desenvolvimento. De modo que, no caso do Plano Apell em São Sebastião, deve haver um diálogo de mão dupla que incorpore os atores locais (seus valores e demandas) no processo decisório e de governança do risco do empreendimento já instalado.

Para além dessa avaliação e diálogo, é necessário, ainda, adensar o conhecimento da população diretamente exposta à situação de risco, com o estudo das características sociodemográficas das populações por setores censitários e bairros, o que permite um olhar mais apurado do lugar, em articulação com as demais escalas possíveis de análise, pois a dimensão de tais

\section{Referências}

AXINN, W. G.; PEARCE, L. D. Motivations for mixed method social research. In: Mixed method data collection strategies. Cambridge: Cambridge University Press, 2007. (New Perspectives on Anthropological and Social Demography).

BESSE, Jean-Marc. Ver a terra: seis ensaios sobre a paisagem e a geografia. São Paulo: Perspectiva, 2006.

BOHOLM, A. The cultural nature of risk: can there be an Anthropology of uncertainty? Ethnos, v. 68, n. 2, p. 159-178, 2003.

BURTON, I.; KATES, R. W.; WHITE, G. F. The environment as hazard. New York: Oxford University, 1978.

COSTA, H. S. M. Indústria, produção do espaço e custos socioambientais: reflexões a partir do exemplo do Vale do Aço, Minas Gerais. In: ENCONTRO NACIONAL DE ESTUDOS POPULACIONAIS, 10., 1996, Caxambu. Anais... Belo Horizonte: ABEP, 1996.

CUNHA, Í. Conflito ambiental em águas costeiras: relação porto-cidade no Canal de São Sebastião. Revista Ambiente \& Sociedade, Campinas, v. 6, n. 2, p. 83-98, jul./dez. 2003.

CUNHA, R. D. S. Avaliação da estratégia da comunicação de riscos ambientais na preparação do público para acidentes de grande porte: estudo de caso do Plano Apell em São Sebastião, SP. 2008. 167 f. Dissertação (Mestrado em Educação, Ad- empreendimentos leva seus efeitos muito além da sua vizinhança imediata.

Os estudos de população e ambiente (P-A) têm se esforçado em avançar nos estudos multiescalares, incluindo a microescala, para que os nexos causais e as relações possam ser melhor compreendidas, potencializando assim ajustes nas teorias e modelos explicativos em escalas maiores (D'ANTONA et al., 2007). O que ainda não foi incorporado com a mesma intensidade é a necessidade de compreender o nível de informação da população, sua experiência ambiental e os elementos que medeiam sua percepção e atitudes frente ao ambiente (TUAN, 1980). Nos cenários de mudanças ambientais atuais, conseguir articular estratégias metodológicas que esquadrinhem o fenômeno em várias escalas e os níveis de informação da população afetada será fundamental para acompanhar a manifestação local de processos globais, o que o caso estudado revela com força exemplar.

ministração e Comunicação) - Universidade São Marcos, São Paulo, 2008 .

CUTTER, S. Vulnerability to environmental hazards. Progress in Human Geography, London, v. 20, n. 4, p. 529-539, 1996.

DAGNINO, R. S.; CARPI JR., S. Risco ambiental: conceitos e aplicações. Climatologia e Estudos da Paisagem, Rio Claro, v. 2, n. 2, 2007.

D'ANTONA, A.; CAK, A. D.; VANWEY, L Efeitos da escala da análise em estudos de mudança da cobertura da terra entre Santarém e Altamira, no Pará, Brasil. In: HOGAN, D. J.; MARANDOLA JR., E. (Org.). Dinâmica populacional e mudança ambiental: cenários para o desenvolvimento brasileiro. Campinas: NEPO/UNICAMP; UNFPA, 2007.

DEFESA CIVIL DE SÃO SEBASTIÃO. Plano de Ação de Emergência: acidentes tecnológicos. São Sebastião, 2010. (Mimeo).

DE PAULA, L. T.; MARANDOLA JR., E. Memória e experiência no estudo de vulnerabilidade do lugar. In: ENCONTRO DE GEÓGRAFOS DAAMÉRICA LATINA, 12., 2009, Montevideo. Anais... Montevideo, 2009.

DI GIULIO, G. M. Comunicação e governança do risco: exemplos de comunidades expostas à contaminação por chumbo 
no Brasil e Uruguai. 327 f. Tese (Doutorado) - Instituto de Filosofia e Ciências Humanas, Universidade Estadual de Campinas, Campinas, 2010.

DOUGLAS, M.; WILDAVSKY, A. Risk and culture. California: University of California Press, 1982.

DRUCK, G.; FRANCO, T. A degradação do trabalho e os riscos industriais no contexto da globalização, reestruturação produtiva e das políticas neoliberais. In: FRANCO, T. (Org.). Trabalho, riscos industriais e meio ambiente: rumo ao desenvolvimento sustentável? Salvador: EDUFBA/CRH/FFCH/ UFBA, 1997.

FRANÇA, A. A Ilha de São Sebastião: estudo de geografia humana. 195 f. Dissertação (Mestrado) - Faculdade de Filosofia, Ciências e Letras, Universidade de São Paulo, São Paulo, 1954.

FUNDAÇÃO IBGE. Censo Demográfico 2000. Rio de Janeiro, 2000a.

$2000 \mathrm{~b}$

. Malha digital do Censo Demográfico. Rio de Janeiro,

. Censo Demográfico 2010. Rio de Janeiro, 2010.

GIDDENS, A. As consequências da modernidade. São Paulo: UNESP, 1991.

HOGAN, D. J. População, pobreza e poluição em Cubatão. In: MARTINE, G. População, meio ambiente e desenvolvimento: verdades e contradições. Campinas: Editora UNICAMP, 1993.

. A relação entre população e ambiente: desafios para a demografia. In: TORRES, H. G.; COSTA, H. (Org.). População e meio ambiente: debates e desafios. São Paulo: SENAC, 2000.

et al. (Org.). Urbanização e vulnerabilidade socioambiental: o caso de Campinas. In: (Org.). Migração $e$ ambiente nas aglomerações urbanas. Campinas: NEPO/ UNICAMP, 2001.

; MARANDOLA JR., E. Vulnerabilidade e perigos naturais nos estudos de população e ambiente. In: (Org.). Dinâmica populacional e mudança ambiental: cenários para o desenvolvimento brasileiro. Campinas: NEPO/UNICAMP; UNFPA, 2007.

KATES, Robert W. The perception of storm hazard on the shores of megalopolis. In: LOWENTHAL, David. (Ed.). Environmental perception and behavior. The University of Chicago, Department of Geography, 1967. p. 60-74. [Research Paper n. 109]

KAZTMAN, R.; FILGUEIRA, F. As normas como bem público e privado: reflexões nas fronteiras do enfoque "ati- vos, vulnerabilidade e estrutura de oportunidades" (AVEO). In: CUNHA, J. M. P. (Org.). Novas metrópoles paulistas: população, vulnerabilidade e segregação. Campinas: NEPO/ UNICAMP, 2006. 616 p.

MARANDOLA JR., E. Habitar em risco: mobilidade e vulnerabilidade na experiência metropolitana. $278 \mathrm{f}$. Tese (Doutorado em Geografia) - Instituto de Geociências, Universidade Estadual de Campinas, Campinas, 2008.

; HOGAN, D. J. Vulnerabilidade e riscos: entre geografia e demografia. Revista Brasileira de Estudos de População, São Paulo, v. 22, n. 1, p. 29-53, jan./jun.2005.

. As dimensões da vulnerabilidade. São Paulo em Perspectiva, v. 20, n. 1, p. 33-43, 2006.

Em direção a uma demografia ambiental? Avaliação e tendências dos estudos de população e ambiente no Brasil. Revista Brasileira de Estudos de População, São Paulo, v. 24, n. 2, p. 191-223, jul./dez. 2007.

; __ . Vulnerabilidade do lugar vs. vulnerabilidade sociodemográfica: implicações metodológicas de uma velha questão. Revista Brasileira de Estudos de População, São Paulo, v. 26, n. 2, p. 161-181, jul./dez. 2009.

; MODESTO, F. Percepção dos perigos ambientais

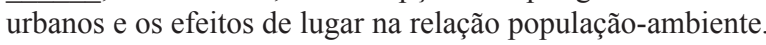
Revista Brasileira de Estudos de População, São Paulo, v. 29, n. 1, p. 7-35, jan./jun. 2012.

MERLEAU-PONTY, M. Fenomenologia da percepção. Tradução: Reginaldo di Piero. Rio de Janeiro: Freitas Bastos, 1971.

OLIVEIRA, Lívia de. Contribuição dos estudos cognitivos à percepção geográfica. Geografia, Rio Claro, v. 2, n. 3, p. 61-72, abr. 1977.

PINHEIRO, José Q. Mapas cognitivos de mundo, tempo na experiência ambiental, lugar e sustentabilidade. In: OLIVEIRA, Lívia; FERREIRA, Yoshiya N.; GRATÃO, Lúcia H. B.; MARANDOLA JR., Eduardo. (Orgs.). Geografia, percepção e cognição do meio ambiente. Londrina: Edições Humanidades, 2006. p. 67-100.

POFFO, I. Vazamentos de óleo no litoral norte do Estado de São Paulo: análise histórica. 175 f. Dissertação (Mestrado) - Programa de Pós-Graduação em Ciências Ambientais, Universidade de São Paulo, São Paulo, 2000.

PORTO, M. F. S.; FREITAS, C. M. Indústria química brasileira, acidentes químicos ampliados e vulnerabilidade social. In: TORRES, H. G.; COSTA, H. (Org.). População e meio ambiente: debates e desafios. São Paulo: SENAC, 2000. 
REIS, H. S. O espaço portuário de São Sebastião no contexto da geografia portuária brasileira. 237 f. Dissertação (Mestrado em Geografia Humana) - Faculdade de Filosofia, Letras e Ciências Humanas, Universidade de São Paulo, São Paulo, 2011.

RENN, O. Risk governance: coping with uncertainty in a complex world. London: Earthscan, 2008.

SANTOS, Francine Modesto dos. Populações em situação de risco ambiental em São Sebastião, litoral norte de São Paulo. 151 f. Dissertação (Mestrado em Demografia) - Instituto de Filosofia e Ciências Humanas, Universidade Estadual de Campinas, Campinas, 2011.

SAARINEN, Thomas F. Perception of drought hazard on the great plains. Chicago: Department of Geography, University of Chicago, 1966. [Research Paper n. 106]

SARACENI, V. Atlas Ambiental: São Sebastião, SP, Brasil. São Paulo: Vistadivina, 2010.

SILVA, G. O. Angra I e a melancolia de uma era: um estudo sobre a construção social do risco. Niterói: EdUFF, 1999.

SLOVIC, P. The perception of risk. London: Earthscan, 2008.
TORRES, H. G. A demografia do risco ambiental. In: COSTA, H. (Org.). População e meio ambiente: debates e desafios. São Paulo: SENAC, 2000.

TUAN, Yi-Fu. Topofilia. São Paulo: Difel, 1980.

VAINER, Carlos. Grandes projetos e organização territorial: os avatares do planejamento regional. In: MARGULIS, S. (Ed.) Meio ambiente: aspectos técnicos e econômicos. Brasília: IPEA, 1990.

VEYRET, Y. Os riscos: o homem como agressor e vítima do meio ambiente. São Paulo: Contexto, 2007.

VOSS, P. R. Demography as a spatial social science. Population Research and Policy Review, Amsterdam, v. 26, n. 5-6, p. 457-476, 2007.

WEEKS, J. R. The Role of Spatial Analysis in Demographic Research. In: GOODCHILD, M. F.; JANELLE, D. G. (Eds.). Spatially Integrated Social Science. Oxford, England: Oxford University Press, 2004, p.381-399.

WHITE, A.; BURTON, I. Environmental risk assessment. London: John Willey \& Sons, 1980.

Recebido em 11 de março de 2012. Aceito em 19 de junho de 2012. Publicado em dezembro de 2012. 